\title{
Exhaled eicosanoids and biomarkers of oxidative stress in exacerbation of chronic obstructive pulmonary disease
}

Adam Antczak, Maciej Ciebiada, Tadeusz Pietras, Wojciech J. Piotrowski, Zofia Kurmanowska, Paweł Górski

Department of Pneumology and Allergy, Medical University of Lodz, Poland

Submitted: 21 July 2010

Accepted: 30 November 2010

Arch Med Sci 2012; 8, 2: 277-285

DOI: $10.5114 /$ aoms.2012.28555

Copyright $\odot 2012$ Termedia \& Banach

\section{Abstract}

Introduction: Eicosanoids and oxidants play an important role in inflammation, but their role in chronic obstructive pulmonary disease (COPD) is uncertain. In this study we hypothesized that levels of exhaled leukotrienes, prostaglandins and biomarkers of oxidative stress are increased in infectious exacerbations of COPD and that they decrease after antibiotic therapy.

Material and methods: Cysteinyl-leukotrienes (LTs), leukotriene $\mathrm{B}_{4}\left(\mathrm{LTB}_{4}\right)$, prostaglandin $\mathrm{E}_{4}$, hydrogen peroxide $\left(\mathrm{H}_{2} \mathrm{O}_{2}\right)$ and 8-isoprostane were measured in exhaled breath condensate (EBC) in 16 COPD patients with infectious exacerbations (mean age $64 \pm 12$ years, 13 male) on day 1 , during antibiotic therapy (days 2-4), 2-4 days after therapy and at a follow-up visit when stable (21-28 days after therapy).

Results: There was a significant fall in concentration of cys-LTs, $\mathrm{LTB}_{4}$ and 8-isoprostane at visit 3 compared to day 1 (cys-LTs: $196.5 \pm 38.4 \mathrm{pg} / \mathrm{ml}$ vs. $50.1 \pm 8.2 \mathrm{pg} / \mathrm{ml}$, $p<0.002$; LTB L $_{4} 153.6 \pm 25.5 \mathrm{pg} / \mathrm{ml}$ vs. $71.9 \pm 11.3 \mathrm{pg} / \mathrm{ml}, p<0.05 ; 8$-isoprostane: $121.4 \pm 14.6 \mathrm{pg} / \mathrm{ml}$ vs. $56.1 \pm 5.2 \mathrm{pg} / \mathrm{ml}, p<0.03$, respectively). Exhaled $\mathrm{H}_{2} \mathrm{O}_{2}$ was higher on day 1 compared to that at visits 2 and $3(0.74 \pm 0.046 \mu \mathrm{M}$ vs. 0.52 $\pm 0.028 \mu \mathrm{M}$ and $0.35 \pm 0.029 \mu \mathrm{M}, p<0.01$ and $p<0.01$, respectively). Exhaled $\mathrm{PGE}_{2}$ levels did not change during exacerbations of COPD. Exhaled eicosanoids and $\mathrm{H}_{2} \mathrm{O}_{2}$ in $\mathrm{EBC}$ measured at the follow-up visit (stable COPD) were significantly higher compared to those from healthy subjects.

Conclusions: We conclude that eicosanoids and oxidants are increased in infectious exacerbations of COPD. They are also elevated in the airways of stable COPD patients compared to healthy subjects.

Key words: chronic obstructive pulmonary disease, exhaled eicosanoids, 8-isoprostane, exhaled breath condensate.

\section{Introduction}

Chronic obstructive pulmonary disease (COPD) is characterized by the progressive development of airflow limitation associated with chronic inflammation [1]. The most important pathological changes are found within the small airways and are characterized by an increased number of macrophages, neutrophils and CD8+ T cells, features which are also found in bronchial biopsies [1]. There is also an increase in macrophages and neutrophils in bronchoalveolar lavage fluid and induced sputum [2]. Furthermore, increased neutrophils in the airways are related to the rate of progression of airway obstruction [3]. Smoking, which is the most important risk factor, increases neutrophil recruitment to the lungs [4], possibly by stimulating bronchial

\author{
Corresponding author: \\ Maciej Ciebiada MD, PhD \\ Department of Pneumology \\ and Allergy \\ Medical University of Lodz \\ 22 Kopcinskiego \\ 90-153 Lodz, Poland \\ Phone: 4842 678-21-29, \\ 48426776699 \\ Fax: 48426782129 \\ E-mail: \\ maciej_ciebiada@op.pl
}


epithelium and macrophages to produce the neutrophil chemoattractant interleukin-8 (IL-8) [5]. Moreover, levels of IL-8 and leukotriene $\mathrm{B}_{4}\left(\mathrm{LTB}_{4}\right)$, which are also chemotactic for neutrophils, are increased in the sputum of patients with COPD [6]. In contrast to asthma, eosinophils are not increased except during exacerbations [7].

There is a complex interaction between cells and mediators in COPD, resulting in progressive changes in small airways and parenchymal damage [1]. It is postulated that macrophages play a critical role, since they are 5 to 10 times increased and when activated are capable of producing all the pathological changes of COPD. They are activated by cigarette smoke to release neutrophil chemoattractants and other mediators of inflammation including eicosanoids [5].

There is overwhelming evidence that oxidative stress may have an important role in COPD [8]. Hydrogen peroxide $\left(\mathrm{H}_{2} \mathrm{O}_{2}\right)$ levels in exhaled breath condensate of patients with COPD are increased, particularly during exacerbations [9]. Plasma antioxidant capacity is decreased in patients with acute exacerbations of COPD [10]. It has also been clearly shown that oxidative overburden leads to lipid peroxidation in the airway of patients with COPD as reflected by greater exhaled ethane and 8-isoprostane levels compared to healthy subjects [11].

Eicosanoids are important inflammatory mediators in asthma, but their role in COPD remains unclear. The $\mathrm{LTB}_{4}$ was detected in nasal lavage [12], sputum and BAL fluid in patients with stable COPD and levels of $\mathrm{LTB}_{4}$ in sputum and BAL correlate with other markers of inflammation such as myeloperoxidase and elastase activity [13]. Moreover, serum $\mathrm{LTB}_{4}$ levels in patients with COPD are higher than in healthy subjects [14]. In contrast, Piperno et al. demonstrated that $\mathrm{LTC}_{4}$ but not $\mathrm{LTB}_{4}$ is detectable in the plasma of patients with COPD [15]. However, plasma levels of leukotrienes are difficult to interpret due to release from inflammatory cells and metabolism. Cys-LTs are potent bronchoconstrictors and play an important role in asthma, particularly in the aspirin-sensitive type [16]. They have also been detected in the sputum of patients with chronic bronchitis [17]. The prostaglandin $\mathrm{E}_{2}\left(\mathrm{PGE}_{2}\right)$ relaxes airway smooth muscles and exerts potent anti-inflammatory activity [18]. It is postulated that the failure in a PGE $\mathrm{E}_{2}$-braking mechanism with increased sensitivity to inhibition by NSAIDs contributes to the overproduction of cys-LTs in aspirin-induced asthmatic patients [16].

Exhaled breath condensate (EBC) provides a non-invasive and easy-to-perform means of looking at the local inflammatory process in the airways, without the need to undertake invasive procedures, such as bronchoscopy. Most of the studies to explore the role of eicosanoids in COPD have used invasive techniques or the assessment of media- tors and their metabolites in plasma or urine. Concentrations of eicosanoids in these biological fluids are more likely to reflect systemic, rather than respiratory tract inflammation. An increasing body of evidence suggests that $E B C$ is a useful way to monitor markers of inflammation and oxidative stress in various respiratory tract diseases.

Exhaled cys-LTs and $\mathrm{PGE}_{2}$ are markers of inflammation in the airways. The $\mathrm{LTB}_{4}$ plays an important role in neutrophil recruitment and activation the site of inflammation. 8-isoprostane and $\mathrm{H}_{2} \mathrm{O}_{2}$ are biomarkers of oxidative stress in breath condensate in inflammatory airway diseases such as asthma, COPD, and cystic fibrosis [19].

Accordingly, the aim of this study was to determine eicosanoids, 8-isoprostane and $\mathrm{H}_{2} \mathrm{O}_{2}$ at various time points in COPD patients hospitalized for an infectious exacerbation of COPD and treated with antibiotics, and to investigate the relationship between these inflammatory markers and clinical variables (airflow limitation and respiratory failure).

\section{Material and methods}

\section{Study population}

Sixteen patients with severe infectious exacerbations of COPD (mean age $64 \pm 12$ years, 13 male), and 13 healthy age-matched controls (mean age $57 \pm 19$ years, 10 male) were recruited for this study (Table I). Patients from the control group had no history of any respiratory disease or respiratory infection, they were non-smokers and they did not suffer from any other disease that could exclude them from the study. The COPD was diagnosed by a history of cough and sputum production for more than 2 consecutive years and for most days in a consecutive 3-month period and spirometry criteria according to GOLD standards [1]. Exacerbation of COPD was defined as "an event in the natural course of the disease characterized by a change in the patient's baseline dyspnoea, cough and/or sputum that is beyond normal day-to-day variations, is acute in onset and may warrant a change in regular medication" [1]. The severity of exacerbation was assessed on the basis of patients' history before the exacerbation (duration of worsening, previous hospitalisations, previous treatment), comorbidities, symptoms, physical diagnosis, and measurements of arterial blood gases [1]. In this study exacerbation of COPD was characterized by increased purulent sputum together with increased dyspnoea and cough. Other inclusion criteria were forced expiratory volume in $1 \mathrm{~s}\left(\mathrm{FEV}_{1}\right)>50 \%$ predicted, at least 3 episodes of exacerbation of COPD in the past year requiring treatment with an antibiotic, and age $\geq 40$ years. Exclusion criteria were a known or suspected hypersensitivity to cephalosporins or macrolides, cystic fibrosis, bronchiectasis or active pulmonary malignancies, immunocompromised patients, and patients 
Table I. Characteristics of study population

\begin{tabular}{|c|c|c|c|c|c|c|c|c|c|}
\hline No & $\begin{array}{c}\text { Age } \\
\text { [years] }\end{array}$ & $\begin{array}{c}\text { Body } \\
\text { temperature } \\
{\left[{ }^{\circ} \mathrm{C}\right]}\end{array}$ & WBC & $\begin{array}{l}\text { Neutrophil } \\
\text { absolute }\end{array}$ & $\begin{array}{c}\text { Current } \\
\text { smoking } \\
\text { status } \\
\text { [cigarettes/ } \\
\text { day] }\end{array}$ & $\begin{array}{c}\text { Cumulative } \\
\text { smoking } \\
\text { habit } \\
\text { [pack years] }\end{array}$ & Pathogen & $\begin{array}{c}\mathrm{FEV}_{1} \\
{[\% \text { pred.] }}\end{array}$ & $\begin{array}{c}\mathrm{FEV}_{1} / \mathrm{FVC} \\
{[\%]}\end{array}$ \\
\hline 1. $\sigma^{\pi}$ & 55 & 38.4 & 8.4 & 5.43 & Non-smoking & 30 & $\begin{array}{c}\text { Staphylococcus } \\
\text { aureus, } \\
\text { Streptococcus } \\
\text { pneumoniae }\end{array}$ & 69.5 & 65 \\
\hline 2. 우 & 70 & 36.6 & 12.3 & 8.08 & 20 & 50 & $\begin{array}{c}\text { S. aureus, } \\
\text { S. pneumoniae }\end{array}$ & 56.9 & 60 \\
\hline 3. $\hat{0}$ & 58 & 38.2 & 9.2 & 6.6 & 10 & 15 & S. pneumoniae & 74.3 & 69 \\
\hline 4. +9 & 76 & 38.0 & 10.8 & 8.55 & 20 & 30 & S. pneumoniae & 55.3 & 58 \\
\hline $5 . \hat{\sigma}$ & 60 & 37.8 & 13.5 & 10.52 & 20 & 45 & No pathogen isolated & 69.9 & 67 \\
\hline 6. 0 & 58 & 36.0 & 7.6 & 5.29 & 20 & 20 & Candida sp. & 72.1 & 66 \\
\hline 7. $\sigma^{\pi}$ & 66 & 36.8 & 6.9 & 5.33 & 25 & 40 & S. pneumoniae & 49.9 & 57 \\
\hline $8 . \hat{0}$ & 56 & 38.6 & 7.8 & 4.77 & 20 & 30 & S. aureus & 68.6 & 63 \\
\hline 9. 0 & 60 & 38.3 & 11.2 & 7.85 & 40 & 120 & $\begin{array}{l}\text { Klebsiella } \\
\text { pneumoniae }\end{array}$ & 54.9 & 60 \\
\hline 10. $\delta$ & 77 & 38.0 & 11.6 & 8.83 & 40 & 90 & S. aureus & 66.3 & 67 \\
\hline 11. $\hat{\sigma}$ & 43 & 38.0 & 18.7 & 17.15 & Non-smoking & 45 & S. aureus & 45.7 & 50 \\
\hline 12. 万 & 56 & 37.2 & 16.1 & 14.59 & 20 & 60 & Proteus vulgaris & 79.9 & 68 \\
\hline 13. $\sigma^{\lambda}$ & 57 & 38.0 & 8.2 & 5.64 & 20 & 30 & $\begin{array}{c}\text { S. aureus. } \\
\text { S. pneumoniae }\end{array}$ & 59.9 & 63 \\
\hline 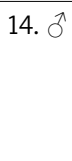 & 77 & 38.0 & 4.7 & 3.92 & 15 & 37.5 & $\begin{array}{c}\text { S. aureus. } \\
\text { S. pneumoniae, } \\
\text { Pseudomonas } \\
\text { aeruginosa }\end{array}$ & 62 & 60 \\
\hline 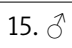 & 71 & 37.6 & 8.7 & 5.09 & 20 & 40 & S. pneumoniae & 52.5 & 59 \\
\hline 16. 우 & 69 & 36.4 & 12.1 & 10.2 & Non-smoking & 35 & Escherichia coli & 53.6 & 61 \\
\hline
\end{tabular}

receiving systemic steroids. Due to exacerbation all patients were treated with inhaled steroids $(1000 \mu \mathrm{g}$ of budesonide or equivalent as an alternative to systemic steroids [1]) and they had been immediately admitted to the hospital. They continued steroid therapy through the entire hospitalisation (inhaled steroids with or without systemic steroids at a dose of $<30 \mathrm{mg}$ per day of prednisone or equivalent up to 7 days). Bronchodilators were allowed in the study including inhaled or nebulized ipratropium bromide and albuterol. Long-acting $\beta_{2}$-agonists were used (formoterol up to $54 \mu \mathrm{g} /$ day). All subjects completed an informed written consent form, and the study was approved by the Ethics Committee of the Medical University of Lodz.

\section{Study design}

This was a randomized, open label, controlled, single-centre study to compare changes in exhaled eicosanoids and $\mathrm{H}_{2} \mathrm{O}_{2}$ in patients with exacerbation of COPD treated for at least 7 days with oral roxithromycin (7 patients, $150 \mathrm{mg}$, twice daily) or oral cefuroxime axetil (9 patients, $500 \mathrm{mg}$ twice daily) randomly allocated $(1: 1)$ to the patients. Average duration of treatment was $7.3 \pm 0.6$ days. Patients were assessed, exhaled breath condensate was obtained, and spirometry and arterial blood gases measurements were done at the baseline visit (visit 1), during therapy (days 2-4), at the end of therapy (2-4 days after therapy) and at a follow-up visit (21-28 days after therapy) (Table II). A sputum specimen for bacteriological evaluation (gram staining, culture and susceptibility testing) was collected at visit 1 .

\section{Exhaled breath condensate}

Breath condensate samples were obtained using a condensing tubing system, as previously described [20]. Briefly, patients were asked to breathe through the collection tube for $15 \mathrm{~min}$. The collection part of the tube was covered with dry ice. 
Table II. Exhaled eicosanoids and $\mathrm{H}_{2} \mathrm{O}_{2}$ in stable COPD patients and healthy subjects

\begin{tabular}{|lccc|}
\hline Parameter & $\begin{array}{c}\text { COPD } \\
(n=16)\end{array}$ & $\begin{array}{c}\text { Healthy } \\
(n=11)\end{array}$ & $\begin{array}{c}\text { Value } \\
\text { of } p\end{array}$ \\
\hline Cys-LTs $[\mathrm{pg} / \mathrm{ml}]$ & $41.7 \pm 6.83$ & $22.4 \pm 3.25$ & $<0.02$ \\
\hline $\mathrm{LTB}_{4}[\mathrm{pg} / \mathrm{ml}]$ & $75.8 \pm 10.71$ & $40.1 \pm 3.41$ & $<0.003$ \\
\hline $\mathrm{PGE}_{2}[\mathrm{pg} / \mathrm{ml}]$ & $41.1 \pm 2.09$ & $20.4 \pm 5.21$ & $<0.004$ \\
\hline 8-Isoprostane $[\mathrm{pg} / \mathrm{ml}]$ & $60.9 \pm 3.84$ & $31.3 \pm 4.27$ & $<0.001$ \\
\hline $\mathrm{H}_{2} \mathrm{O}_{2}[\mathrm{mM}]$ & $0.35 \pm 0.029$ & $0.17 \pm 0.28<0.001$ \\
\hline
\end{tabular}

Means \pm standard error of the mean are shown

The temperature in the tube vicinity ranged from $-43^{\circ} \mathrm{C}$ to $-32^{\circ} \mathrm{C}$ and allowed collection of all vapours and droplets present in the exhaled air. At the end of the collection, the tube was removed from the container and 2-6 $\mathrm{ml}$ aliquots of condensate were transferred to Eppendorf tubes and stored at $-80^{\circ} \mathrm{C}$ for not more than 4 weeks. Due to the impact of cigarette smoke on oxidants and eicosanoids present in exhaled breath, our patients refrained from smoking for at least $12 \mathrm{~h}$ before measurement. It was easy because they were in exacerbation of COPD and most of them did not even smoke due to their symptoms.

\section{Measurement of leukotrienes}

Cys-LTs concentration in breath condensate was measured using a specific enzyme immunoassay (EIA) kit (Cayman Chemical, Ann Arbour, MI). The antiserum used in this assay has $100 \%$ cross-reactivity with $\mathrm{LTC}_{4}$ and $\mathrm{LTD}_{4}, 67 \%$ with $\mathrm{LTE}_{4}$, and $<0.01 \%$ each with $15-\mathrm{HETE}, 12-\mathrm{HETE}, \mathrm{LTB}_{4}, \mathrm{PGF}_{2}$. The detection limit of the assay is $13 \mathrm{pg} / \mathrm{ml}$. This kit has been used to measure concentrations of cys-LTs in rat and human urine, plasma, and BAL fluid [12, 21].

The $\mathrm{LTB}_{4}$ was measured using the EIA kit (Cayman (hemical) in breath condensate. The antiserum used in this assay has $100 \%$ cross-reactivity with $\mathrm{LTB}_{4}, 39 \%$ with 6-trans $\mathrm{LTB}_{4}$, and $<0.01 \%$ each with $\mathrm{LTC}_{4}, \mathrm{LTE}_{4}, \mathrm{LTD}_{4}$, and $\mathrm{LTF}_{4}$, and a detection limit of $4.43 \mathrm{pg} / \mathrm{ml}$.

\section{Measurement of immunoreactive 8-isoprostane}

8-isoprostane concentration in breath condensate was measured using an EIA kit (Cayman Chemical). The antiserum used in this assay has 100\% cross-reactivity with 8 -epi-PGF $2 \alpha, 0.2 \%$ each with $\mathrm{PGF}_{2 \alpha}, \mathrm{PGF}_{3 \alpha}, \mathrm{PGE}_{1}, \mathrm{PGE}_{2}$, and $0.1 \%$ with 6-keto$\mathrm{PGF}_{1 \alpha}$. The detection limit of the assay is $4 \mathrm{pg} / \mathrm{ml}$.

\section{Measurement of immunoreactive prostaglandin $\mathrm{E}_{2}$}

The $P G E_{2}$ concentration in breath condensate was measured using a specific EIA kit (Cayman
Chemical). The antiserum used in this assay has $100 \%$ cross-reactivity with $\mathrm{PGE}_{2}, 43 \%$ with $\mathrm{PGE}_{3}$, $18.7 \%$ with $\mathrm{PGE}_{1}$, and $0.1 \%$ each with $\mathrm{PGF}_{2 \alpha}, \mathrm{PGA}_{1}$, $\mathrm{PGA}_{2}$, and the detection limit at $4^{\circ} \mathrm{C}$ is $15 \mathrm{pg} / \mathrm{ml}$. For all measurements $50 \mu \mathrm{l}$ aliquots of the condensate were used.

\section{Detection of hydrogen peroxide}

The $\mathrm{H}_{2} \mathrm{O}_{2}$ was detected according to the method of Ruch [22] and readings were expressed in $\mu \mathrm{M}$ using the regression equation $Y=\left(X-X_{0}\right) 0.0676$ (where $\mathrm{Y}=$ micromoles of $\mathrm{H}_{2} \mathrm{O}_{2}$ per litre of $\mathrm{EBC}$; $X=$ intensity of emission; $X_{0}=$ intensity of emis sion given by reference sample receiving distilled water instead of EBC). For all measurements $600 \mu \mathrm{l}$ aliquots of condensate mixed with horseradish peroxidase solution $(1 \mathrm{U} / \mathrm{ml})$ were used. The $\mathrm{H}_{2} \mathrm{O}_{2}$ concentration was determined spectrofluorimetrically using a Perkin Elmer Spectrometer (Norwalk, USA).

\section{Spirometry}

Post-bronchodilation spirometry was performed before the start of the treatment with inhaled steroids in the outpatient clinic or in the hospital (visit 1), at visit 2 and the post-therapy visit (visit 3) and at the follow-up visit with a computer-assisted spirometer (Lung Test 1000, MES Dymek, Dabrowski SA, Kracow, Poland) according to standardized guidelines. Values were expressed as percentage of predicted values.

\section{Arterial blood gases}

A sample of arterialised capillary blood from the finger pulp was taken in all COPD patients and $\mathrm{pO}_{2}$ and $\mathrm{pCO}_{2}$ were assessed to determine the presence of respiratory failure.

\section{Statistical analysis}

Statistical analyses included a two-way analysis of variance (ANOVA). Repeated measures test (Friedman test) was used to compare groups. Linear regression analysis was used to assess the relationship between measured parameters. Readings below the method detection limit were arbitrarily assumed as half way between the detection limit and 0 . All data are expressed as means \pm standard error of the mean and significance was defined as a $p$ value of $<0.05$. Statistica $5.1 \mathrm{PL}$ for Windows software (StatSoft Polska, Cracow, Poland) was used for analyses.

\section{Results}

Table II shows mean exhaled eicosanoid and $\mathrm{H}_{2} \mathrm{O}_{2}$ levels from stable COPD patients (as assessed at follow-up visit) and healthy control subjects. Mean volume of exhaled breath condensate was 
$2.22 \pm 0.31 \mathrm{ml}$ at visit $1,2.37 \pm 0.42$ at visit 2 , and 2.41 \pm 0.25 at visit 3 for COPD patients. Stable COPD patients had significantly higher levels of all eicosanoids compared to healthy subjects.

\section{Leukotrienes}

Significantly greater levels of exhaled cys-LTs were observed at visit 1 compared to those at visit 2 and the post-therapy visit $(196.5 \pm 38.41$ vs. 78.6 \pm 12.28 and $50.1 \pm 8.15 \mathrm{pg} / \mathrm{ml}, p<0.03$ and $p<0.002$, respectively) and at the follow-up visit (41.7 $\pm 6.83 \mathrm{pg} / \mathrm{ml}, p<0.002$ ) (Figure 1). There were significantly higher levels of exhaled $\mathrm{LTB}_{4}$ at visit 1 compared to those at visit 3 but not during antibiotic therapy $(153.6 \pm 25.51$ vs. $132.0 \pm 29.31$ and 71.9 $\pm 11.25 \mathrm{pg} / \mathrm{ml}, p<0.03$ and $p<0.05$, respectively). There was also a significant difference between levels of $\mathrm{LTB}_{4}$ in exhaled breath condensate on day 1 and at the follow-up visit $(75.8 \pm 10.71 \mathrm{pg} / \mathrm{ml}$, $p<0.03)$. There were no differences between cephalosporin and macrolide treated groups.

\section{Prostaglandin $\mathrm{E}_{2}$}

In contrast to changes in exhaled cys-LTs and $\mathrm{LTB}_{4}$ levels, exhaled $\mathrm{PGE}_{2}$ levels did not change during exacerbations of COPD ( $47.0 \pm 3.71$ vs. $40.3 \pm 2.49$ and $36.9 \pm 3.09 \mathrm{pg} / \mathrm{ml}$, respectively, $p>0.05$ ) (Figure 3) and remained higher even at follow-up compared to healthy subjects ( $41.0 \pm 2.09$ vs. 20.4 $\pm 5.21 \mathrm{pg} / \mathrm{ml}, p<0.004)$. There were no differences in exhaled cys-LTs and $\mathrm{LTB}_{4}$ concentration between cephalosporin and macrolide treated groups.

\section{8-Isoprostane}

8-isoprostane levels in expired breath condensate during exacerbation of COPD are shown in Figure 4. There were significantly greater levels of exhaled 8-isoprostane on day 1 compared to those during therapy and at post-therapy visits (121.4 \pm 14.59 vs. $92.4 \pm 6.28$ and $56.1 \pm 5.15 \mathrm{pg} / \mathrm{ml}, p<0.05$ and $p<0.03$, respectively) and at the follow-up visit $(60.9 \pm 3.84 \mathrm{pg} / \mathrm{ml})$. There was also a significant difference in 8 -isoprostane levels between visits 2 and $3(p<0.001)$. There were no differences between cephalosporin and macrolide treated groups.

\section{Hydrogen peroxide}

As seen in Figure 5, there were significantly greater levels of exhaled $\mathrm{H}_{2} \mathrm{O}_{2}$ on day 1 compared to those during therapy and at post-therapy visits $(0.74 \pm 0.046$ vs. $0.52 \pm 0.028$ and $0.35 \pm 0.029 \mu \mathrm{M}$, $p<0.001$ and $p<0.001$, respectively) and at the follow-up visit $(0.33 \pm 0.022 \mu \mathrm{M}, p<0.001)$. There was also a significant difference in $\mathrm{H}_{2} \mathrm{O}_{2}$ levels between visits 2 and $3(p<0.01)$. There were no differences

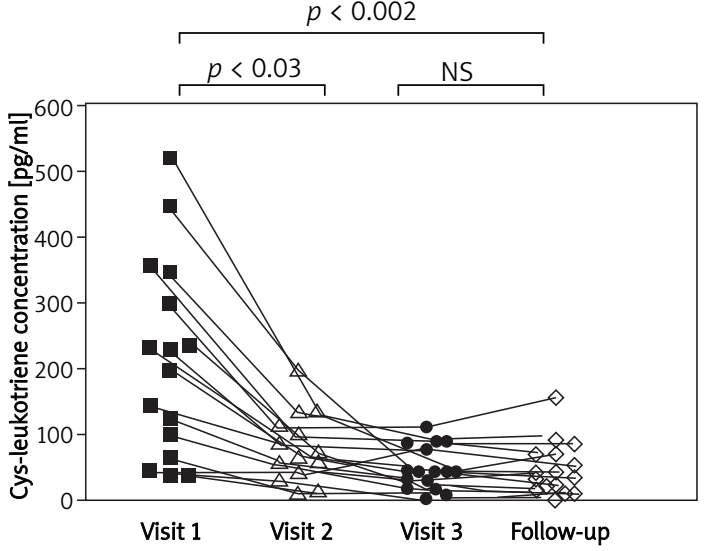

Figure 1. Cys-LTs in expired breath condensate of exacerbated COPD patients

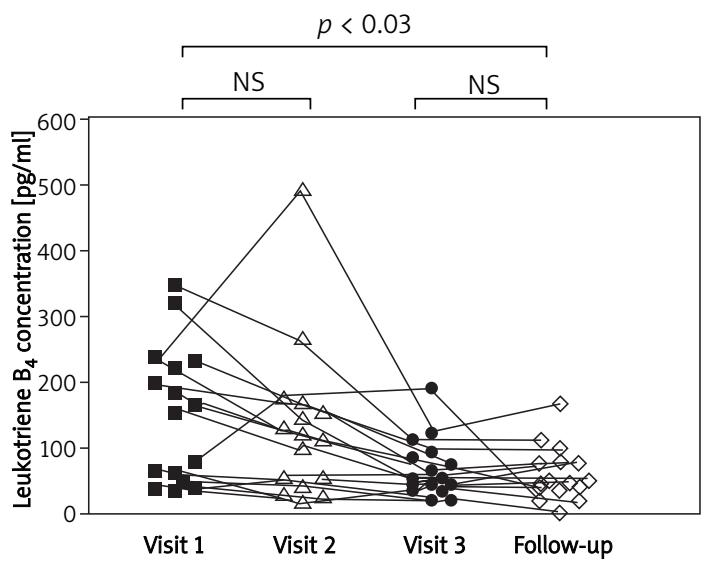

Figure 2. The $\mathrm{LTB}_{4}$ in expired breath condensate of exacerbated COPD patients

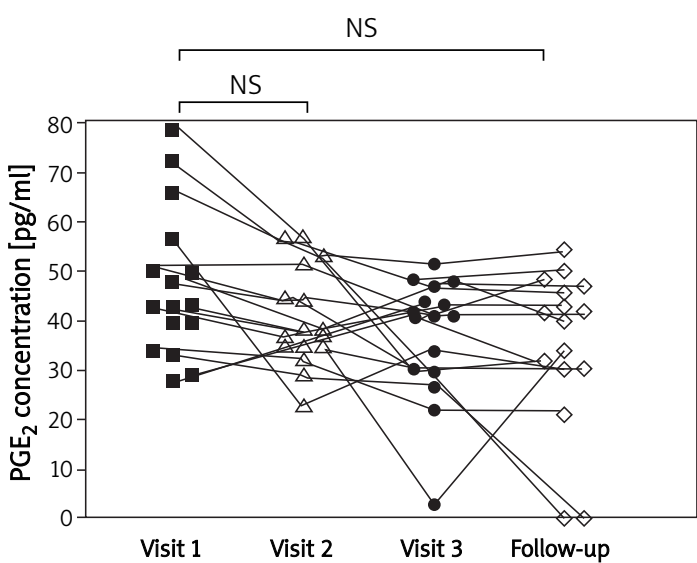

Figure 3. The $\mathrm{PGE}_{2}$ in expired breath condensate of exacerbated COPD patients

between cephalosporin and macrolide treated groups. There was a positive correlation between exhaled 8-isoprostane and $\mathrm{H}_{2} \mathrm{O}_{2}$ levels at visit 1 $(r=0.62, p<0.05)$ (Figure 6). There were no correlations between exhaled eicosanoids and $\mathrm{H}_{2} \mathrm{O}_{2}$ and clinical status, smoking status and pulmonary function tests at all visits. 


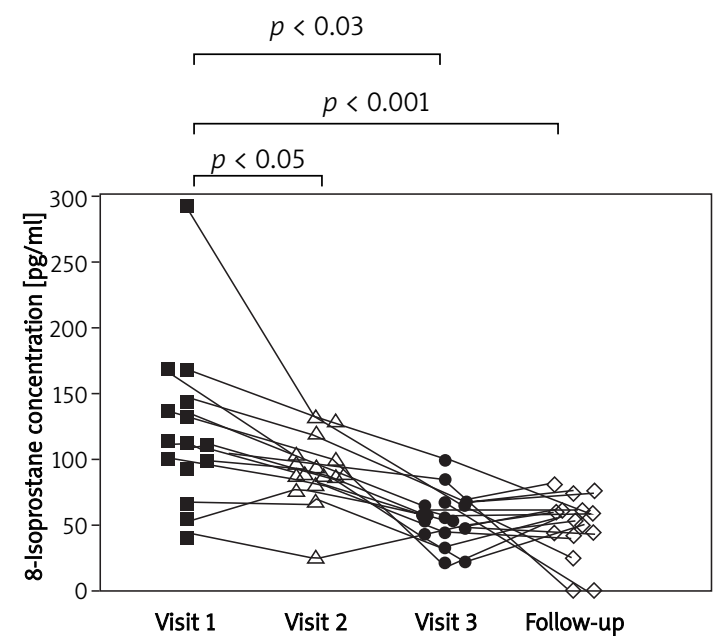

Figure 4. The 8-isoprostane levels in expired breath condensate of exacerbated COPD patients

\section{Pulmonary function tests and $\mathrm{pO}_{2}$}

Significantly lower $\mathrm{FEV}_{1} \%$ pred. values were observed at visit 1 compared to those at visit 2 and the post-therapy visit ( $62 \pm 2$ vs. $69 \pm 1$ and 73

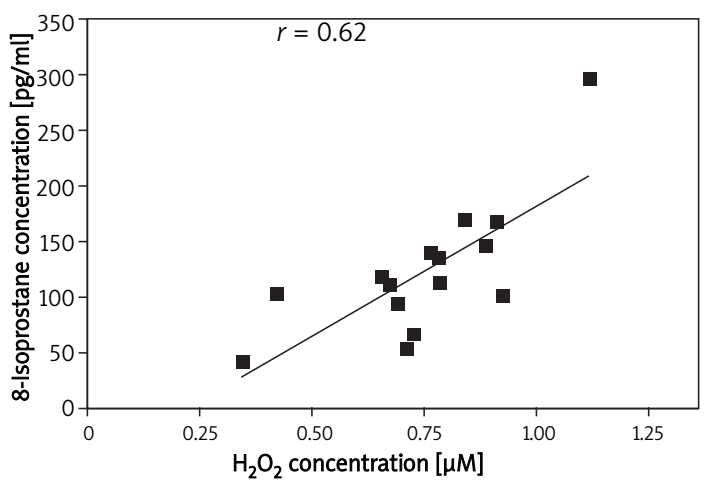

Figure 6. Positive correlation between 8-isoprostane and $\mathrm{H}_{2} \mathrm{O}_{2}$ levels in expired breath condensate of exacerbated COPD patients at visit 1 (day 1 )

A

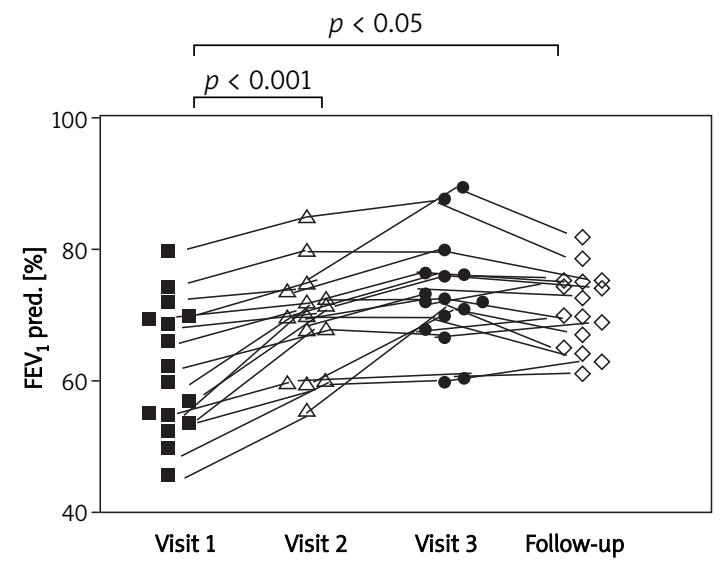

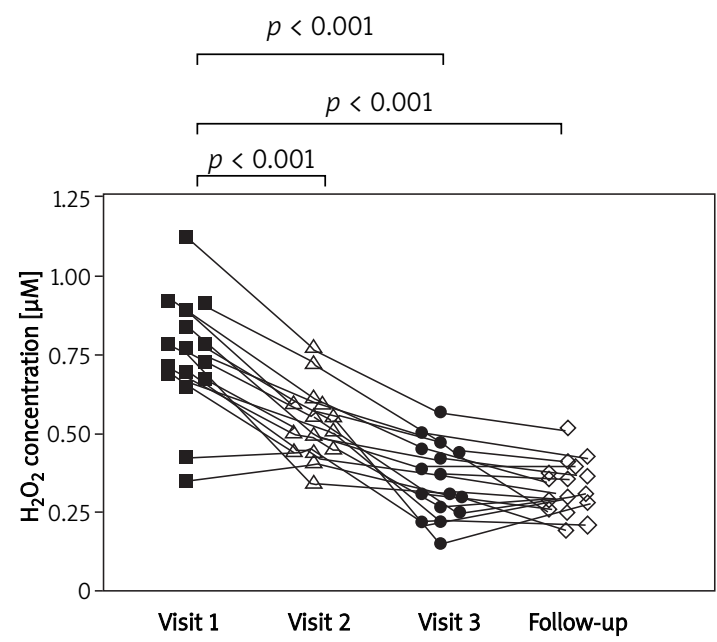

Figure 5. The $\mathrm{H}_{2} \mathrm{O}_{2}$ in expired breath condensate of exacerbated COPD patients

$\pm 2 \mathrm{pg} / \mathrm{ml}, p<0.001$ and $p<0.001$, respectively) and at the follow-up visit $(71 \pm 2 \mathrm{pg} / \mathrm{ml}, p<0.001)$ (Figure $7 \mathrm{~A}$ ). There were significantly lower $\mathrm{pO}_{2}$ values at visit 1 compared to those at visit 3 and during antibiotic therapy ( $55 \pm 1$ vs. $73 \pm 2$ and $68 \pm 2 \mathrm{~mm} \mathrm{Hg}$, $p<0.001$ and $p<0.001$, respectively). There was also a significant difference between $\mathrm{pO}_{2}$ on day 1 and at the follow-up visit $(74 \pm 2 \mathrm{~mm} \mathrm{Hg}, p<0.001)$ (Figure $7 \mathrm{~B}$ ). There were no differences between cephalosporin and macrolide treated groups.

\section{Discussion}

We demonstrated that eicosanoids (cys-LTs, $\mathrm{LTB}_{4}$, 8-isoprostane) and $\mathrm{H}_{2} \mathrm{O}_{2}$, well known for their proinflammatory activity, are significantly elevated in patients during acute exacerbations of COPD and that they decrease during treatment, although they remain in higher concentrations in stable COPD patients compared to healthy subjects. Similarly, there are increased levels of exhaled $P E_{2}$ in expired breath condensate from exacerbated COPD

B

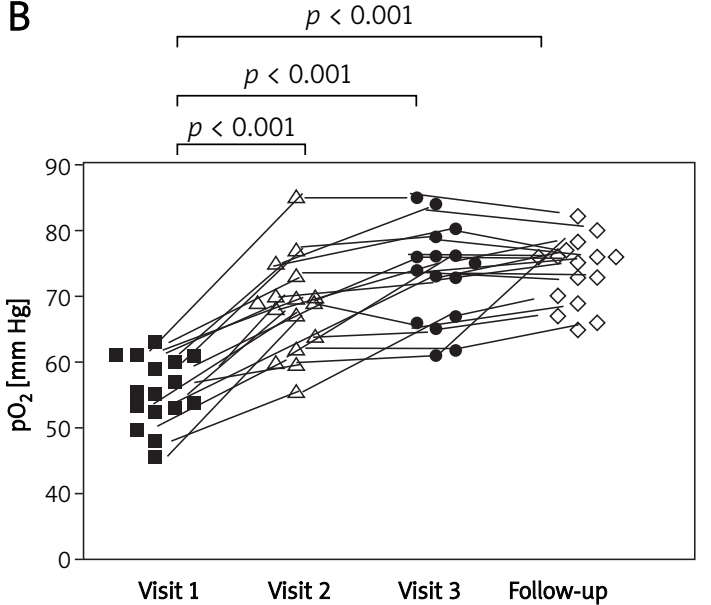

Figure 7. Changes of $\mathrm{FEV}_{1}(\mathrm{~A})$ and $\mathrm{pO}_{2}(\mathrm{~B})$ in patients with exacerbation of COPD 
patients but they do not change in the course of treatment and are significantly higher than those from healthy subjects.

In this study comparative measurements of proinflammatory cys-LTs, $\mathrm{LTB}_{4}, 8$-isoprostanes and $\mathrm{H}_{2} \mathrm{O}_{2}$ and anti-inflammatory (bronchoprotective) $\mathrm{PGE}_{2}$ have been performed, using exhaled breath condensate from patients with bacterial exacerbations of COPD, and healthy controls. Exhaled breath condensate provides a non-invasive and low-tech means of looking at the local inflammatory process in the airways. It is very well tolerated by patients and no adverse effects have been reported. This technique has been used to study oxidative stress in COPD subjects [11] and an increasing body of evidence suggests that it is a useful way to monitor markers of inflammation and oxidative stress in various respiratory tract diseases, such as asthma, COPD and cryptogenic fibrosing alveolitis [23].

Altered metabolism of arachidonic acid may be one of the mechanisms of bronchoconstriction in COPD patients, particularly during exacerbation. Our study now demonstrates local overproduction of cysLTs, $\mathrm{LTB}_{4}$ and PGE 2 in the airways in COPD and is consistent with the study showing increased plasma levels of $\mathrm{LTE}_{4}$ in acute exacerbations of COPD which decrease after steroid treatment [24]. Increased levels of $\mathrm{LTB}_{4}$ have also been found in sputum from COPD patients with $\alpha 1$-antitrypsin deficiency [6]. There are few data on the effects of antibiotic treatment on eicosanoid profiles and it can only be speculated that both cephalosporins and roxithromycin may reduce the number of activated cells that release pro-inflammatory cytokines in the airways by blocking their influx into the lung [25]. Roxithromycin has some immunoregulatory effects in chronic respiratory tract infection reflected by reducing levels of $\mathrm{LTB}_{4}$ in epithelial lining fluid [25].

The fact that leukotrienes but also prostaglandins levels are increased during exacerbations suggests that there might be an increase in 5-lipoxygenase enzyme activity in COPD patients. Eosinophils are increased in bronchial mucosa in COPD during exacerbations compared to stable COPD and may be responsible for increased cys-LTs.

In contrast to elevated cys-LTs and $\mathrm{LTB}_{4}, \mathrm{PGE}_{2}$ levels in exhaled breath condensate of COPD patients are high even after treatment and at follow-up. It is possible that $\mathrm{PGE}_{2}$ may play a bronchoprotective role. Moreover, $\mathrm{PGE}_{2}$ may inhibit the release of $\mathrm{LTB}_{4}$ from neutrophils in a concentrationdependent manner [26]. Our results clearly show that local levels of $P G E_{2}$ in the airways are increased in COPD compared with healthy subjects and this might be an adaptive mechanism to protect the airways from bronchoconstrictive agents which, as we show in this study, are increased even in clinically stable subjects. Moreover, as $\mathrm{PGE}_{2}$ levels did not change throughout the study it seems to be an argument that a decrease in the levels of other markers is not related to a decrease in the volume of droplets logically expected in exacerbated patients with increased secretions. If a changed volume of droplets produced in the airways was responsible for observed changes in mediators, the change would also be seen in all mediators including $\mathrm{PGE}_{2}$.

8-Isoprostane, a stable prostaglandin-like arachidonate product formed on membrane phospholipids by the action of reactive oxygen species, is postulated to be a reliable biomarker of lipid peroxidation caused by oxygen reactive species and to represent a quantitative measure of oxidative stress in vivo [27]. The 8-isoprostane appears to reflect oxidative stress in breath condensate and is progressively increased with the severity of asthma, and its levels are particularly elevated in aspirininduced asthma [28]. It is also reported to be increased in expired breath condensate in both stable and exacerbated COPD patients [19]. In this study we found further increases in the levels of exhaled 8-isoprostane in exacerbations of COPD patients. It has been well documented that an oxidant-antioxidant imbalance in favour of the latter is a hallmark of COPD. 8-isoprostane levels decreased during treatment, but remained higher in stable COPD patients compared to healthy subjects. It is not certain if 8-isoprostane is involved in the pathogenesis of COPD, but 8-isoprostane can cause contraction of human bronchi in vitro [29].

We also found an increase in $\mathrm{H}_{2} \mathrm{O}_{2}$ in exhaled breath condensate during acute exacerbations of COPD, which is in agreement with a previous study [9]. Furthermore, there is a correlation between exhaled $\mathrm{H}_{2} \mathrm{O}_{2}$ and 8-isoprostane levels, providing further evidence that oxidative stress is increased during exacerbation. The increased content of $\mathrm{H}_{2} \mathrm{O}_{2}$ and 8-isoprostane in expired breath condensate of COPD subjects is likely to be due to increased oxidant production and subsequent lipid peroxidation in the bronchial lining fluid. This is likely to be due to an increase in the number of activated inflammatory cells such as neutrophils and macrophages in the airways. Some healthy subjects also had measurable exhaled 8-isoprostane and $\mathrm{H}_{2} \mathrm{O}_{2}$, which is consistent with studies showing the peroxidedependent spontaneous chemiluminescence of human breath and with our previous study in which $22 \%$ of non-smoking subjects revealed a detectable content of $\mathrm{H}_{2} \mathrm{O}_{2}$ in expired breath condensate [30].

Abrogation of oxidative stress and lipid peroxidation in exacerbations of COPD by antibiotics may be the effect of a reduction in the number and activation of inflammatory cells producing reactive oxygen species and eicosanoids. 
However, we did not find any correlations between exhaled eicosanoids, $\mathrm{H}_{2} \mathrm{O}_{2}$ and 8-isoprostane and clinical status, smoking status and pulmonary function tests at all visits in COPD patients. Although there have been some trials that showed such correlations [31], there have been a few studies that could not find any significant association between concentration of inflammatory mediators and lung function impairment in COPD patients measured with $\operatorname{FEV}_{1}[11,31]$. The lack of correlation in our study could be due to the low number of participants. Another explanation is that $\mathrm{FEV}_{1}$ and inflammatory mediators are different markers of COPD. Concentration of exhaled mediators (i.e. $\mathrm{H}_{2} \mathrm{O}_{2}, 8$ isoprostane, leukotrienes) reflects oxidative stress while $\mathrm{FEV}_{1}$ reflects calibre of airways, and it is possible that oxidative stress is present even without airflow limitation. The lack of correlation does not diminish the importance of the fact that the EBC mediators could be used in the study of inflammation in the airways of patients with COPD.

In conclusion, we have shown that there are increased levels of both pro-inflammatory and antiinflammatory eicosanoids and also increased oxidative stress as reflected by increased exhaled 8-isoprostane and $\mathrm{H}_{2} \mathrm{O}_{2}$ during infectious exacerbations of COPD. Although reduced after antibiotic and antiinflammatory treatment, eicosanoids and markers of oxidative stress remain in higher concentrations locally in the airways, as reflected by the increased levels in exhaled breath condensate of patients with stable COPD compared to normal subjects. These mediators may play a pathophysiological role in COPD and measurement of these markers in the exhaled air may provide a useful and non-invasive approach to study inflammation in the airways during exacerbations.

\section{Acknowledgments}

This study has been done with financial support from the Polish Research Committee (grant no. PBZ/KBN/004/CD/T-11/2000) and from the Medical University of Lodz no. 502-11-827.

\section{References}

1. Global Strategy for the Diagnosis, Management, and Prevention of Chronic Obstructive Pulmonary Disease. NHLBI/WHO Report, 2006 updated 2009.

2. Hodge SJ, Hodge GL, Holmes M, Reynolds PN. Flow cytometric characterization of cell populations in bronchoalveolar lavage and bronchial brushings from patients with chronic obstructive pulmonary disease. Cytometry B Clin Cytom 2004; 61: 27-34.

3. Stanescu D, Sanna A, Veriter C, et al. Airway obstruction, chronic expectoration, and rapid decline of FEV1 in smokers are associated with increased levels of sputum neutrophils. Thorax 1996; 51: 267-71.
4. MacNee W, Wiggs BB, Berzberg AS, Hogg JC. The effect of cigarette smoking on neutrophil kinetics in human lungs. N Engl J Med 1989; 6: 287-95.

5. Mio T, Romberger DJ, Thompson AB, Robbins RA, Reinnard SI. Cigarette smoke induces interleukin-8 release from human bronchial epithelial cells. Am J Respir Crit Care Med 1997; 155: 1770-6.

6. Hill AT, Campbell EJ, Bayley DL, Hill SL, Stockley RA. Evidence for excessive bronchial inflammation during an acute exacerbation of chronic obstructive pulmonary disease in patients with alpha(1)-antitrypsin deficiency (PiZ). Am J Respir Crit Care Med 1999; 160: 1968-75.

7. Papi A, Romagnoli M, Baraldo S, et al. Partial reversibility of airflow limitation and increased exhaled NO and sputum eosinophilia in chronic obstructive pulmonary disease. Am J Respir Crit Care Med 2000; 162: 1773-7.

8. Repine JE, Bast A, Lankhorst I. Oxidative stress in chronic obstructive pulmonary disease. Am J Respir Crit Care Med 1997; 156: 341-57.

9. Dekhujzen PNR, Aben KK, Dekker I, et al. Increased exhalation of hydrogen peroxide in patients with stable and unstable chronic obstructive pulmonary disease. Am J Respir Crit Care Med 1996; 154: 813-6.

10. Rahman I, Morrison D, Donaldson K, MacNee W. Systemic oxidative stress in asthma, COPD, and smokers. Am J Respir Crit Care Med 1996; 154: 1055-60.

11. Montuschi P, Collins JV, Ciabattoni G, et al. Increased 8-isoprostane as in vivo biomarker of lung oxidative stress in patients with COPD and healthy smokers. Am J Respir Crit Care Med 2000; 162: 1175-7.

12. Piotrowska VM, Piotrowski WJ, Kurmanowska Z, Marczak J, Górski P, Antczak A. Rhinosinusitis in COPD: symptoms, mucosal changes, nasal lavage cells and eicosanoids. Int J COPD 2010; 5: 107-17.

13. Hill AT, Bayley D, Stockley RA. The interpretation of sputum inflammatory markers in patients with chronic bronchitis. Am J Respir Crit Care Med 1999; 160: 893-8.

14. Seggev IS, Thornton WH, Edes TE. Serum leukotriene $B_{4}$ levels in patients with chronic obstructive pulmonary disease. Chest 1991; 99: 289-91.

15. Piperno D, Pacheco Y, Hosni R, et al. Increased plasma levels of atrial natriuretic peptide, renin activity, and leukotriene $\mathrm{C}_{4}$ in chronic obstructive pulmonary disease. Chest 1993; 104: 454-9.

16. Szczeklik A, Stevenson DD. Aspirin-induced asthma: advances in pathogenesis and management. J Allergy Clin Immunol 1999; 104: 5-13.

17. Zakrzewski JT, Barnes NC, Costello JF, Piper PJ. Lipid mediators in cystic fibrosis and chronic obstructive pulmonary disease. Am Rev Respir Dis 1987; 136: 779-82.

18. Jakobsson PJ, Thoren S, Morgenstern R, Mancici J, Ford-Huchinson A, Person B. Identification of human prostaglandin E synthase: a microsomal, glutathionedependent, inducible enzyme, constituting a potential novel drug target. Proc Natl Acad Aci USA 1999; 96: 7220-5.

19. Montuschi P, Kharitonov SA, Ciabattoni G, et al. Increased 8-isoprostane as non-invasive biomarker of oxidative stress in cystic fibrosis. Thorax 2000; 55: 205-9.

20. Antczak A, Nowak D, Krol M, Shariati B, Kurmanowska Z. Increased hydrogen peroxide and thiobarbituric acidreactive products in expired breath condensate of asthmatic patients. Eur Respir J 1997; 10: 1231-41.

21. Piotrowski WJ, Antczak A, Marczak J, Nawrocka A, Kurmanowska Z, Górski P. Eicosanoids in exhaled breath condensate and BAL fluid of patients with sarcoidosis. Chest 2007; 132: 589-96. 
22. Ruch W, Cooper PH, Baggiolini M. Assay of $\mathrm{H}_{2} \mathrm{O}_{2}$ production by macrophages and neutrophils with homovanillic acid and horseradish peroxidase. J Immunol Methods 1983; 63: 347-57.

23. Kharitonov SA, Barnes PJ. Exhaled markers of pulmonary diseases. Am J Respir Crit Care Med 2001; 163: 1693-722.

24. Shindo K, Fukumura M, Miyakawa K. Plasma levels of leukotriene $\mathrm{E} 4$ during clinical course of bronchial asthma and the effect of oral prednisolone. Chest 1994; 105: 1038-41.

25. Nakamura H, Fuijishima S, Inoue T. Clinical and immunoregulatory effects of roxithromycin in chronic respiratory tract infection. Eur Respir J 1999; 13: 1371-9.

26. Ham EA, Sodermann DD, Zanetti ME, Dougherty HW, McCanley E, Kuehl FA. Inhibition by prostaglandins of leukotriene $\mathrm{B}_{4}$ release from activated neutrophils. Proc Natl Acad Sci USA 1983; 80: 4349-53.

27. Dworski R, Murray JJ, Roberts LJ, et al. Allergen-induced synthesis of F2-isoprostanes in atopic asthmatics. Evidence for oxidant stress. Am J Respir Crit Care Med 1999; 160: 1947-51.

28. Antczak A, Montuschi P, Kharitonov SA, Gorski P, Barnes PJ. Increased exhaled cysteinyl-leukotrienes and 8-isoprostane in aspirin-induced asthma. Am J Respir Crit Care Med 2002; 166: 301-6.

29. Montuschi P. Isoprostanes and other exhaled markers in respiratory diseases. Eur Respir Rev 1999; 9: 249-53.

30. Nowak D, Antczak A, Król M, et al. Increased content of hydrogen peroxide in expired breath of cigarette smokers. Eur Respir J 1996; 9: 652-7.

31. Kostikas K, Papatheodorou G, Psathakis K, Panagou P, Loukides S. Oxidative stress in expired breath condensate of patients with COPD. Chest 2003; 124: 1373-80. 